\title{
Serum microRNAs levels in primary focal segmental glomerulosclerosis
}

\author{
Xiaoyi Cai • Zhengkun Xia $\cdot$ Chunni Zhang $\cdot$ Yang Luo • \\ Yuanfu Gao $\cdot$ Zhongmin Fan $\cdot$ Mengyuan Liu • \\ Ying Zhang
}

Received: 15 November 2012 /Revised: 27 January 2013 / Accepted: 4 February 2013 /Published online: 6 March 2013

(C) The Author(s) 2013. This article is published with open access at Springerlink.com

\begin{abstract}
Background MicroRNAs (miRNAs, miRs) are involved in most physiological, developmental, and pathological processes. miR-192 and miR-205 are expressed preferentially in the renal cortex and closely relevant to the renal cell biology. In the present study, we aim to measure the serum levels of miR-192 and miR-205 and their correlation with clinicopathological data in patients with primary focal segmental glomerulosclerosis (FSGS) and minimal change disease (MCD).

Methods Fifty-six patients ( 35 male, 21 female) with idiopathic nephrotic syndrome (FSGS 30, MCD 26) and 20 healthy controls were enrolled in the study. We quantified the serum levels of miR-192 and miR-205 in patients with FSGS and MCD by RT-qPCR.

Results Patients with FSGS had higher serum levels of miR192 and miR-205 than those with MCD $(324.49 \pm 42.74$ $\mathrm{fmol} / 1$ versus $90.19 \pm 27.14 \mathrm{fmol} / 1, p<0.01,2.25 \pm 0.69$ $\mathrm{fmol} / 1$ versus $0.60 \pm 0.51 \mathrm{fmol} / 1, p<0.01$, respectively). The level of miR-192 was positively correlated with the proteinuria in patients with FSGS and MCD $(r=0.62, p<0.001$, $r=0.84, p<0.001$, respectively). Similarly, the level of miR205 was positively correlated with the proteinuria in patients with FSGS $(r=0.54, p=0.002)$. In addition, the serum level of miR-192 was significantly correlated with the degree of interstitial fibrosis in patients with FSGS $(r=0.342, p<0.05)$.
\end{abstract}

X. Cai $\cdot$ Z. Xia $(\bowtie) \cdot$ Y. Gao $\cdot$ Z. Fan $\cdot$ M. Liu $\cdot$ Y. Zhang Department of Pediatric Nephrology, Jinling Hospital, Nanjing University School of Medicine, 305 East Zhongshan Road, Nanjing 210002 Jiangsu Province, China

e-mail:njxzk@126.com

C. Zhang $\cdot$ Y. Luo

Department of Clinical Laboratory, Jinling Hospital, Clinical School of Medical College, Nanjing University,

210002, Nanjing, People's Republic of China
Conclusions miR-192 and miR-205 have the potential as markers to differentiate FSGS from MCD.

Keywords Focal segmental glomerulosclerosis $\cdot$ Minimal change disease $\cdot$ Nephrotic syndrome $\cdot$ miRNAs

\section{Introduction}

Primary focal segmental glomerulosclerosis (FSGS) and minimal change disease (MCD), lumped together as podocytopathy, are both characterized by heavy proteinuria and the nephrotic syndrome (NS) as well as extensive flattening of podocyte foot process in ultrastructural morphology [1]. However, FSGS often shows lesions as glomerulosclerosis, tubular atrophy, and interstitial fibrosis, followed by therapeutic dilemma, steroid resistance, which shows a tendency to process to end-stage renal disease (ESRD) [2,3]. Currently, clinicians predict the severity and prognosis of the idiopathic nephrotic syndrome in children through their response to steroids, rather than through kidney biopsy, which is the precise approach to distinguish MCD from FSGS. The consequence of an imprecise diagnosis in these children is exposure to the high risk of morbidity due to immunosuppression [4]. To our knowledge, there has not been a reliable biomarker for FSGS and MCD.

MicroRNAs (miRNAs, miRs) appear to play roles in most physiological, developmental, and pathological processes. Many of the miRNAs can be found in extracellular fluid such as plasma, serum [5, 6], and urine [7] in addition to tissues and cells. miRNAs are relatively stable, which makes them ideal as biomarkers for disease. Although plenty of miRNAs are widely expressed in many tissues, some miRNAs are found to be highly organ-specific [8]. miR-192 and miR-205 are expressed preferentially in the renal cortex and closely relevant to the renal cell biology $[9,10]$. miR192 and miR-205 are more abundant in the kidney than 
other organs(rat) [10]. Wang et al. [11] showed miR-192 and miR-205 were found elevated in renal tissues of patients with hypertensive glomerulosclerosis. In the present study, we examine the serum levels of miR-192 and miR-205 and their correlation with clinicopathological data.

\section{Patients and methods}

Patient cohort and blood collection

Fifty-six children and adolescents ( 31 male, 25 female) diagnosed with active idiopathic nephrotic syndrome based on the International Study of Kidney Disease in Children [12] were enrolled in the study. Thirty patients with FSGS and 26 patients with MCD were confirmed by kidney biopsy between March 2011 and April 2012 at the Department of Pediatrics, Jinling Hospital, Nanjing, China. We selected another 20 healthy, age- and sex-matched individuals (12 male, 8 female) as controls. Demographic and clinical data (urinalysis, biochemical results, response to steroid, duration of disease, and current treatment) were obtained at the time of enrollment. Patients with congenital nephrotic syndrome, secondary nephrotic syndrome such as systemic lupus erythematosus (SLE), and idiopathic nephrotic syndrome in remission status were excluded. Steroid-dependent nephrotic syndrome (SDNS) was defined when a patient had two consecutive relapses during corticosteroid therapy, or within 14 days of ceasing therapy. Steroid-dependent nephrotic syndrome (SRNS) was defined as no response to the initial 8 weeks of corticosteroid treatment. Blood samples obtained from all participants were processed immediately. Serum samples were separated by a 15 -min centrifugation at $3,000 \mathrm{rpm}$ and then stored at $-70{ }^{\circ} \mathrm{C}$ until analysis.

Total RNA extraction and quantification

Total RNA was extracted from each serum sample $(100 \mu \mathrm{l})$ using TRIzol Reagent (Invitrogen, Carlsbad, CA, USA) in accordance with the manufacturer's protocols.

We used a TaqMan PCR kit (Applied Biosystems, Foster City, CA, USA) to carry out assays following the manufacturer's instructions. In brief, $2 \mu \mathrm{l}$ of total RNA was reverse transcribed to cDNA using a specific stem-loop RT primer (Applied Biosystems) under the condition of $16{ }^{\circ} \mathrm{C}$ for $30 \mathrm{~min}, 42^{\circ} \mathrm{C}$ for $30 \mathrm{~min}$, and $85^{\circ} \mathrm{C}$ for $5 \mathrm{~min}$. RT-QPCR was performed at $95{ }^{\circ} \mathrm{C}$ for $5 \mathrm{~min}$, followed by 40 cycles at $95{ }^{\circ} \mathrm{C}$ for $15 \mathrm{~s}$ and $60{ }^{\circ} \mathrm{C}$ for $1 \mathrm{~min}$. The results were analyzed on the ABI 7900 Real-Time PCR System (Applied Biosystems). All reactions, including non-template controls, were performed in triplicate. The calibration curves for concentrations of the synthetic mature miR-192 and miR205 calibrators were linear from $10^{2}$ to $10^{5} \mathrm{fmol} / \mathrm{l}$.
Assessment of interstitial fibrosis

Assessment of mesangial proliferation and interstitial fibrosis was determined on $4-\mu \mathrm{m}$ paraffin-embedded sections stained by periodic acid-Schiff stain (PAS). Ten microscopic fields were viewed at magnification of $200 \times$ and scored from 0 to $100 \%$ for each patient. An experienced pathologist blinded to the laboratory results evaluated the degree of mesangial proliferation and interstitial fibrosis.

Statistics

Statistical analysis was performed with the software SPSS 17.0. The results were presented in mean $\pm \mathrm{SD}$. Comparisons were made using the ANOVA analysis followed by SNK test for three parametric groups. Student's $t$ test was used for two parametric groups. Chi-square test was used to examine the differences in proportions between groups. Pearson correlation coefficient $(r)$ was used to test the relationship between miRNAs and clinical parameters. All probabilities were two-tailed. Statistical significance was determined by $p<0.05$.

\section{Results}

The demographic and baseline data of participants are summarized in Table 1. There was no significant difference in age, sex, serum creatinine, urinary protein/creatinine ratio, hepatic function, glomerular filtration rate (GFR), or duration of disease. The proportion of patients receiving distinct therapies were similar $(p=0.53)$, as well as that of the patients' response to the steroid at the time of enrollment $(p=0.83)$. The glomerular filtration rate was estimated using the Schwartz formula [13].

\section{Serum levels of miR-192 and miR-205}

As compared to patients with MCD and healthy controls, patients with FSGS had higher serum concentration of miR$192(324.49 \pm 42.74 \mathrm{fmol} / 1$ versus $90.19 \pm 27.14 \mathrm{fmol} / 1$, $p<0.01,324.49 \pm 42.74 \mathrm{fmol} / 1$ versus $44.81 \pm 26.03 \mathrm{fmol} / 1$, $p<0.01$, respectively) (Fig. 1a). Similarly, patients with FSGS had higher serum concentration of miR-205 than those with MCD and healthy controls $(2.25 \pm 0.69 \mathrm{fmol} / 1$ versus $0.60 \pm 0.51 \mathrm{fmol} / 1, p<0.01,2.25 \pm 0.69 \mathrm{fmol} / 1$ versus $0.72 \pm 0.64 \mathrm{fmol} / 1, p<0.01$, respectively), but there was no difference between MCD and controls $(0.60 \pm 0.51 \mathrm{fmol} / 1$ versus $0.72 \pm 0.64 \mathrm{fmol} / 1, p>0.05$ ) (Fig. $1 \mathrm{~b}$ ).

In the FSGS group, patients received calcineurin inhibitors or not had similar serum miRNAs levels (miR-192: $323.54 \pm 39.75$ versus $327.60 \pm 54.94, p=0.83 ; 2.21 \pm 0.65$ versus $2.39 \pm 0.85, p=0.56$, respectively). The serum levels 
Table 1 The demographic and baseline data of participants

\begin{tabular}{|c|c|c|c|}
\hline Group & FSGS & $\mathrm{MCD}$ & $\mathrm{HC}$ \\
\hline No. & 30 & 26 & 20 \\
\hline $\begin{array}{l}\text { Gender } \\
\quad \text { (male/female) }\end{array}$ & $16 / 14$ & $15 / 11$ & $12 / 8$ \\
\hline Age & $6.67 \pm 2.90$ & $6.84 \pm 3.56$ & $7.50 \pm 3.12$ \\
\hline uPCR (mg/mg) & $5.02 \pm 1.18$ & $4.48 \pm 1.04$ & \\
\hline Serum creatinine $(\mu \mathrm{mol} / \mathrm{l})$ & $41.13 \pm 15.61$ & $38.90 \pm 24.63$ & \\
\hline ALT & $22.10 \pm 4.66$ & $24.00 \pm 5.12$ & \\
\hline AST & $27.10 \pm 5.47$ & $28.54 \pm 5.79$ & \\
\hline GFR $\left(\mathrm{ml} / \mathrm{min} / 1.73 \mathrm{~m}^{2}\right)$ & $139.51 \pm 49.11$ & $152.71 \pm 54.26$ & \\
\hline $\begin{array}{l}\text { Duration of disease } \\
\text { (months) }\end{array}$ & $16.34 \pm 6.87$ & $16.02 \pm 5.32$ & \\
\hline $\begin{array}{l}\text { Treatment } \\
\quad(\text { steroid }+ \text { non-CNI/ } \\
\text { steroid }+\mathrm{CNI})\end{array}$ & $7 / 23$ & $8 / 18$ & \\
\hline $\begin{array}{l}\text { Response to } \\
\text { corticosteroid } \\
\text { (SRNS/SDNS) }\end{array}$ & $17 / 13$ & $14 / 12$ & \\
\hline
\end{tabular}

Student's $t$ test was used for two parametric groups. The Chi-square test was used to examine the differences in proportions between groups FSGS focal segmental glomerulosclerosis, $M C D$ minimal change disease, $H C$ healthy controls, GFR glomerular filtration rate, $u P C R$ urinary protein/creatinine ratio, $C N I$ calcineurin inhibitors, $A L T$ alanine aminotransferase, AST aspartate aminotransferase, SRNS steroid-resistant nephrotic syndrome, SDNS steroid-dependent nephrotic syndrome

of miRNAs did not show any significant difference between patients with distinct therapies within MCD group (miR192: $95.03 \pm 26.71$ versus $79.29 \pm 26.49, p=0.18 ; 0.53 \pm 0.43$ versus $0.77 \pm 0.64, p=0.35$; respectively).

\section{Relation with clinical parameters}

Serum concentration levels of miR-192 and miR-205 had a positive correlation with proteinuria in patients with FSGS (miR-192: $r=0.62, p<0.001$; miR-205: $r=0.54, p=0.002$ ) (Fig. 2a, b). The serum level of miR-192 was also correlated with proteinuria in $\operatorname{MCD}(r=0.84, p<0.001)$ (Fig. 2c). There was no significant relation between particular miRNA level and other clinical parameters.

\section{Relation with interstitial fibrosis}

The degree of mesangial proliferation of FSGS was higher that of MCD $(35.2 \pm 12.3 \%$ versus $16.2 \pm 5.6 \%)$. There was no correlation was found between the serum levels of the miRNAs and the degree of mesangial proliferation in FSGS and MCD. The percentage of interstitial fibrosis was $19.6 \pm 13.7 \%$. The degree of interstitial fibrosis was correlated with serum level of miR-192 $(r=0.342, p<0.05)$, but no significant correlation with that of miR-205.
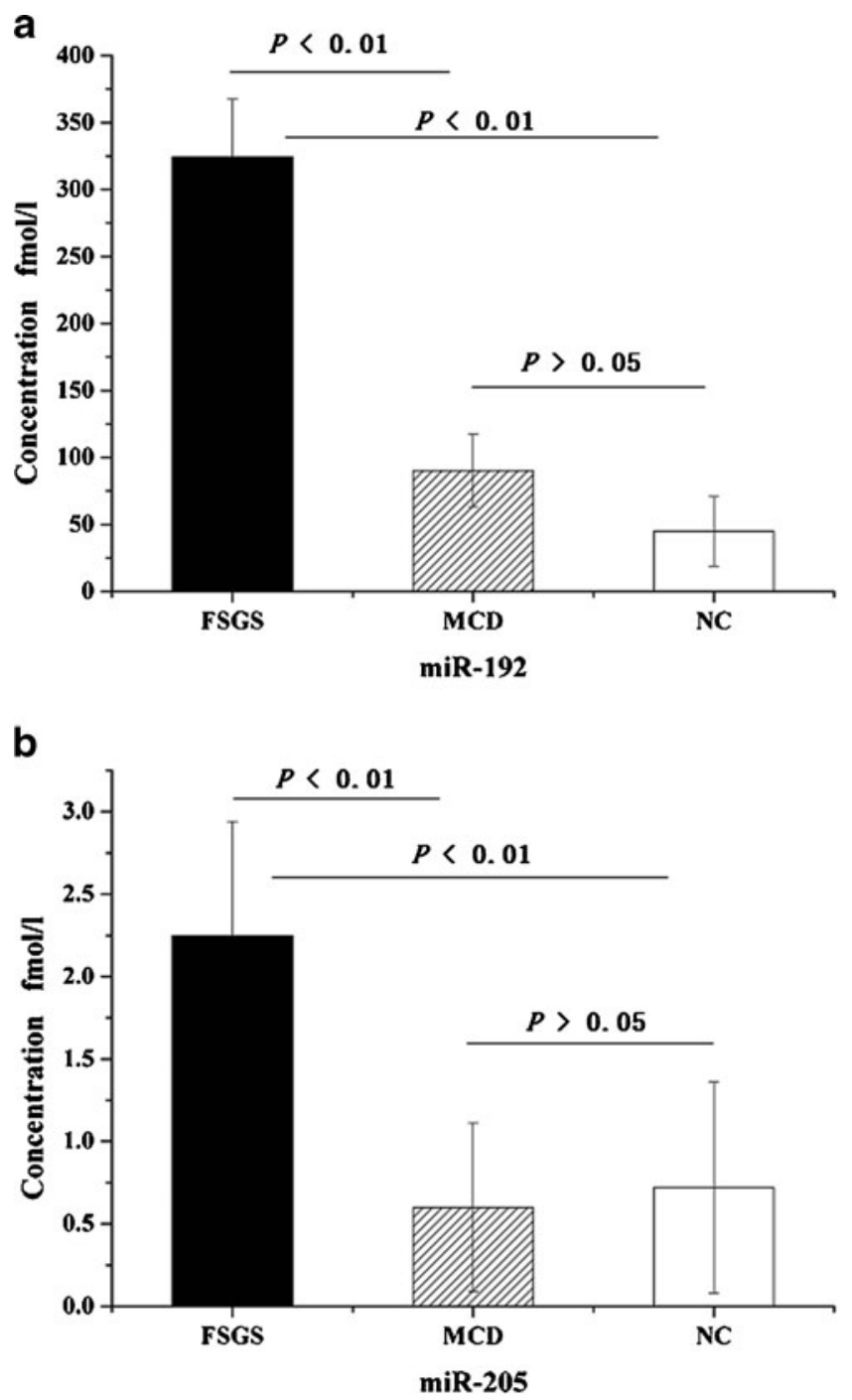

Fig. 1 Comparison of serum concentrations of (a) miR-192 and (b) miR-205 among patients with FSGS, MCD, and HC. Data were compared by ANOVA analysis followed by SNK test. FSGS focal segmental glomerulosclerosis, $M C D$ minimal change disease, $H C$ healthy controls

\section{Discussion}

FSGS and MCD have similar presentations but absolutely different outcomes. We use the responsiveness to steroids to extrapolate the severity of renal histology, however the response was nothing but a time-dependent and elementary way to eschew the confirmation of the exact pathology [14]. In addition, the functional mode of steroids eliminating the proteinuria has not been understood. In the present work, we analyzed the serum miRNAs according to the definite histology including MCD and FSGS rather than responsiveness to steroids.

Historically early FSGS often cannot be distinguished from MCD, when it does not present with glomerulosclerosis or interstitial fibrosis [15]. FSGS and MCD often have heavy proteinuria, while renal fibrosis occurs in FSGS 


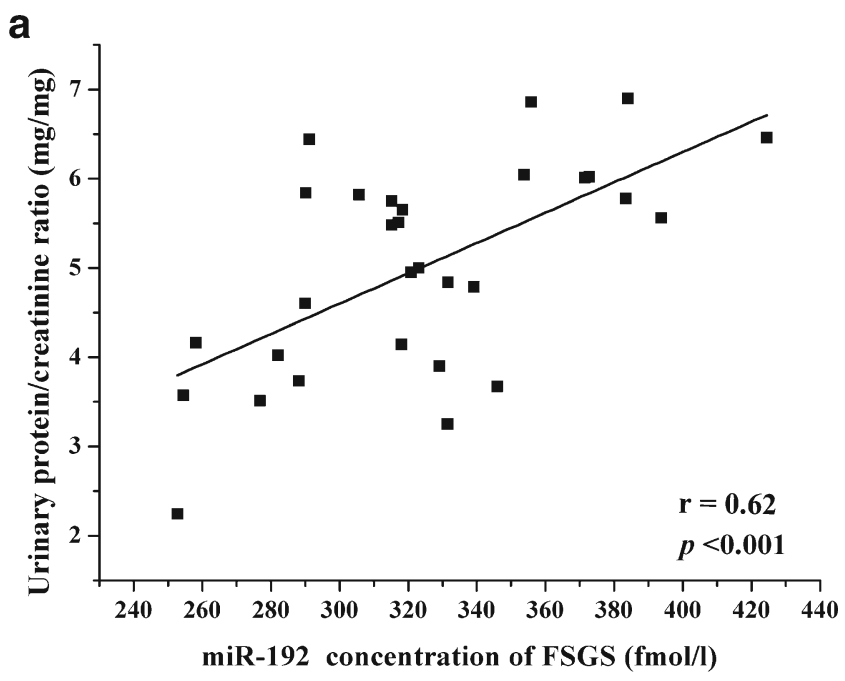

b
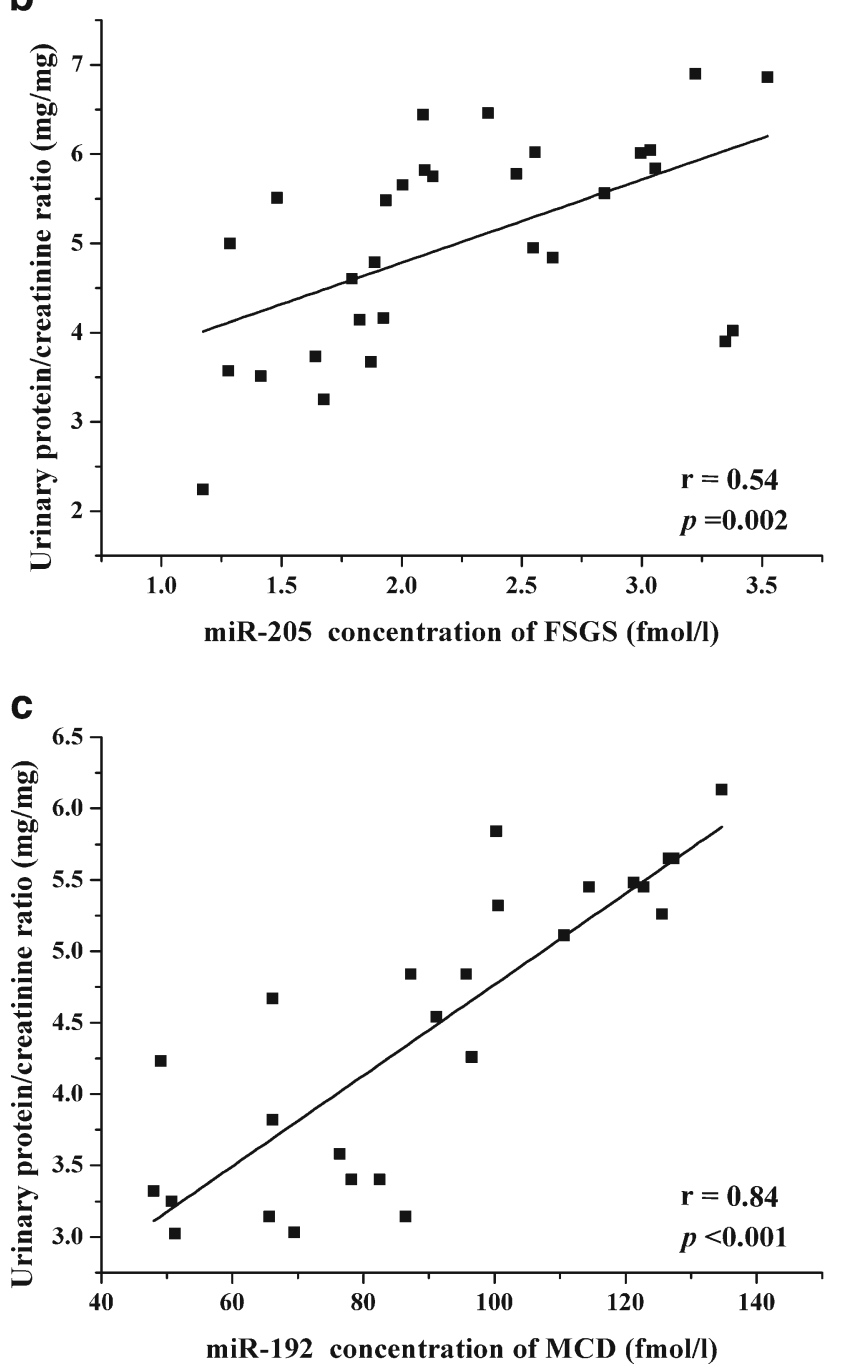

Fig. 2 Correlation between urinary protein and serum concentrations of miR-192 (a), miR-205 in patients with FSGS (b), and miR-192 in patients with MCD (c). Data were compared by Pearson correlation coefficient (r). FSGS focal segmental glomerulosclerosis, $M C D$ minimal change disease predominantly, which indicates that other mechanisms accelerating the process of fibrosis apart from proteinuria [16]. Many miRNAs have been found to play a pivotal role in the physiology and pathogenesis of kidney disease [17, 18]. Tissue specificity and relative stability of miRNAs make them promising candidates as biomarkers to reflect various disease states. miR-192 and miR-205 have been reported in multiple kidney diseases. In the current work, we found that higher levels of serum miR-192 and miR-205 in FSGS compared to that in MCD and healthy controls. miR-192 and miR-205 were positively correlated with proteinuria in patients with FSGS. Results indicated that miR-192 level positively correlated with the degree of renal fibrosis. Our study was consistent with previous studies. Kato et al. [19] showed that elevated miR-192 level in mouse mesangial cell increased the expression of collagen contributing to matrix accumulation and glomerulosclerosis. Kato et al. [20, 21] also identified that increased miR-192 level could lead to glomerulosclerosis in mesangial cell through TGF- $\beta_{1}$ autointroduction and Akt activation. Additionally, Putta et al. [22] found that suppression of miR-192 in diabetic mice attenuated proteinuria and ameliorated renal fibrosis. Multiple evidence has emerged that miR-192 and miR-205 participated in the process of epithelial mesenchymal transition (EMT) [23-26], which was proved to contribute to the renal fibrosis [27-30].

This is an innovative study on analyzing the serum levels of miR-192 and miR-205 in FSGS and MCD. There are some inadequacies. First, the single-centre study limited the sample size. Therefore we do not have enough statistical evidence for a powerful conclusion. Second, the treatment of each patient could be heterogenous, and the drugs they were receiving might affect the results, especially the calcineurin inhibitors. In order to eliminate bias, we compared the serum miRNAs levels between patients with or without calcineurin inhibitors in each group. In each group, the serum levels of miR-192 were similar between patients with distinct treatment, as well as that of miR-205. Additionally, we tested the miRNAs in serum without exploring the cellular sources of them. Kato et al. showed that miR-192 were largely expressed in mesangial cells [20]. Further studies are warranted to explore the underlying mechanism to validate the hypothesis that circulating miRNAs play a part in cell-to-cell communication [6].

In summary, our study, for the first time, showed that serum miR-192 and miR-205 have higher expression levels, which were correlated with the urine protein and the degree of tubulointerstitial fibrosis in patients with FSGS. The results suggest that miR-192 and miR205 have the potential as markers to differentiate FSGS from MCD. The in-depth mechanism by which the miR192 and miR-205 accelerate the progressive process of FSGS needs to be explored. 
Acknowledgments This work was supported by a grant from the National Natural Science Foundation of China (nos. 81270800). We thank Gao Chunlin, Shi Zhuo, Sun Tao, and Peng Hongjun, pediatricians, for the excellent contribution and the patients for their generous involvement in this study. We appreciate Wang Xiaomeng for her excellent suggestions for our manuscript.

Open Access This article is distributed under the terms of the Creative Commons Attribution License which permits any use, distribution, and reproduction in any medium, provided the original author(s) and the source are credited.

\section{References}

1. Nezhad ST, Momeni B, Basiratnia M (2010) Glomerular malondialdehyde levels in patients with focal and segmental glomerulosclerosis and minimal change disease. Saudi J Kidney Dis Transpl 21:886-891

2. Gulati S, Sengupta D, Sharma RK, Sharma A, Gupta RK, Singh U, Gupta A (2006) Steroid resistant nephrotic syndrome: role of histopathology. Indian Pediatr 43:55-60

3. Savin VJ, Sharma R, Sharma M, McCarthy ET, Swan SK, Ellis E, Lovell H, Warady B, Gunwar S, Chonko AM, Artero M, Vincenti F (1996) Circulating factor associated with increased glomerular permeability to albumin in recurrent focal segmental glomerulosclerosis. N Engl J Med 334:878-883

4. Czech KA, Bennett M, Devarajan P (2011) Distinct metalloproteinase excretion patterns in focal segmental glomerulosclerosis. Pediatr Nephrol 26:2179-2184

5. Cortez MA, Calin GA (2009) MicroRNA identification in plasma and serum: a new tool to diagnose and monitor diseases. Expert Opin Biol Ther 9:703-711

6. Mitchell PS, Parkin RK, Kroh EM, Fritz BR, Wyman SK, PogosovaAgadjanyan EL, Peterson A, Noteboom J, O'Briant KC, Allen A, Lin DW, Urban N, Drescher CW, Knudsen BS, Stirewalt DL, Gentleman R, Vessella RL, Nelson PS, Martin DB, Tewari M (2008) Circulating microRNAs as stable blood-based markers for cancer detection. Proc Natl Acad Sci USA 105:10513-10518

7. Hanke M, Hoefig K, Merz H, Feller AC, Kausch I, Jocham D, Warnecke JM, Sczakiel G (2010) A robust methodology to study urine microRNA as tumor marker: microRNA-126 and microRNA182 are related to urinary bladder cancer. Urol Oncol 28:655-661

8. Liang Y, Ridzon D, Wong L, Chen C (2007) Characterization of microRNA expression profiles in normal human tissues. BMC Genomics 8:166

9. Sun Y, Koo S, White N, Peralta E, Esau C, Dean NM, Perera RJ (2004) Development of a micro-array to detect human and mouse microRNAs and characterization of expression in human organs. Nucleic Acids Res 32:e188

10. Tian Z, Greene AS, Pietrusz JL, Matus IR, Liang M (2008) MicroRNAtarget pairs in the rat kidney identified by microRNA microarray, proteomic, and bioinformatic analysis. Genome Res 18:404-411

11. Wang G, Kwan BC, Lai FM, Choi PC, Chow KM, Li PK, Szeto CC (2010) Intrarenal expression of miRNAs in patients with hypertensive nephrosclerosis. Am J Hypertens 23:78-84

12. Eddy AA, Symons JM (2003) Nephrotic syndrome in childhood. Lancet 362:629-639

13. Schwartz GJ, Haycock GB, Edelmann CM Jr, Spitzer A (1976) A simple estimate of glomerular filtration rate in children derived from body length and plasma creatinine. Pediatrics 58:259-263
14. Meyrier AY (2009) Treatment of focal segmental glomerulosclerosis with immunophilin modulation: when did we stop thinking about pathogenesis? Kidney Int 76:487-491

15. Cameron JS, Davlson AM, GrUnfcld JP (1992) Oxford textbook of clinical nephrology. Abstracts of the Renal Association Sheffield UK: 1142

16. Wen Q, Huang Z, Zhou SF, Li XY, Luo N, Yu XQ (2010) Urinary proteins from patients with nephrotic syndrome alters the signalling proteins regulating epithelial-mesenchymal transition. Nephrology (Carlton) 15:63-74

17. Kato M, Arce L, Natarajan R (2009) MicroRNAs and their role in progressive kidney diseases. Clin J Am Soc Nephrol 4:1255-1266

18. Saal S, Harvey SJ (2009) MicroRNAs and the kidney: coming of age. Curr Opin Nephrol Hypertens 18:317-323

19. Kato M, Zhang J, Wang M, Lanting L, Yuan H, Rossi JJ, Natarajan R (2007) MicroRNA-192 in diabetic kidney glomeruli and its function in TGF-beta-induced collagen expression via inhibition of E-box repressors. Proc Natl Acad Sci USA 104:3432-3437

20. Kato M, Arce L, Wang M, Putta S, Lanting L, Natarajan R (2011) A microRNA circuit mediates transforming growth factor-beta1 autoregulation in renal glomerular mesangial cells. Kidney Int 80:358-368

21. Kato M, Putta S, Wang M, Yuan H, Lanting L, Nair I, Gunn A, Nakagawa Y, Shimano H, Todorov I, Rossi JJ, Natarajan R (2009) TGF-beta activates Akt kinase through a microRNAdependent amplifying circuit targeting PTEN. Nat Cell Biol 11:881-889

22. Putta S, Lanting L, Sun G, Lawson G, Kato M, Natarajan R (2012) Inhibiting microRNA-192 ameliorates renal fibrosis in diabetic nephropathy. J Am Soc Nephrol 23:458-469

23. Gregory PA, Bert AG, Paterson EL, Barry SC, Tsykin A, Farshid G, Vadas MA, Khew-Goodall Y, Goodall GJ (2008) The miR-200 family and miR-205 regulate epithelial to mesenchymal transition by targeting ZEB1 and SIP1. Nat Cell Biol 10:593-601

24. Park SM, Gaur AB, Lengyel E, Peter ME (2008) The miR-200 family determines the epithelial phenotype of cancer cells by targeting the E-cadherin repressors ZEB1 and ZEB2. Genes Dev 22:894-907

25. Korpal M, Lee ES, Hu G, Kang Y (2008) The miR-200 family inhibits epithelial-mesenchymal transition and cancer cell migration by direct targeting of E-cadherin transcriptional repressors ZEB1 and ZEB2. J Biol Chem 283:14910-14914

26. Burk U, Schubert J, Wellner U, Schmalhofer O, Vincan E, Spaderna S, Brabletz T (2008) A reciprocal repression between ZEB1 and members of the miR-200 family promotes EMT and invasion in cancer cells. EMBO Rep 9:582-589

27. Rastaldi MP, Ferrario F, Giardino L, Dell'Antonio G, Grillo C, Grillo P, Strutz F, Muller GA, Colasanti G, D’Amico G (2002) Epithelial-mesenchymal transition of tubular epithelial cells in human renal biopsies. Kidney Int 62:137-146

28. Frazier KS, Paredes A, Dube P, Styer E (2000) Connective tissue growth factor expression in the rat remnant kidney model and association with tubular epithelial cells undergoing transdifferentiation. Vet Pathol 37:328-335

29. Fan JM, Ng YY, Hill PA, Nikolic-Paterson DJ, Mu W, Atkins RC, Lan HY (1999) Transforming growth factor-beta regulates tubular epithelial-myofibroblast transdifferentiation in vitro. Kidney Int 56:1455-1467

30. Nangaku M (2004) Mechanisms of tubulointerstitial injury in the kidney: final common pathways to end-stage renal failure. Intern Med 43:9-17 